\title{
Poesía y otredad: de la crítica a la modernidad como génesis de las teorías decoloniales
}

\section{Poetry and Otherness: the Criticism of Modernity as the Genesis of Decolonial Theories}

\author{
Xavier Rodríguez Ledesma ${ }^{1}$ \\ Universidad Pedagógica Nacional (México)
}

Recibido: 19-12-19

Aprobado: 19-01-20

\section{Resumen}

La crítica de Octavio Paz sobre el significado de la modernidad para los países latinoamericanos, sustentada en una visión poética y en una perspectiva otorgada por ser un autor proveniente de la otredad que postulaba la necesidad de que la Razón recuperará su espíritu crítico abandonado a raíz del intento de imponerla como forma hegemónica de pensar el presente, pasado y futuro de toda la humanidad, sentó las bases para lo que hoy en día conocemos como teorías de la decolonialidad. Sin embargo, la reflexión del poeta mexicano es ignorada tanto por las capillas académicas que han pensado la modernidad, como por los pensadores que han asumido al decolonialismo como forma de imaginar el futuro de nuestras sociedades.

El artículo presenta varias de las aportaciones de Octavio Paz a la discusión, concluyendo que su obra debería ser considerada como integrante de la genealogía del pensamiento decolonial.

Palabras-clave: Octavio Paz, Modernidad, Decolonialismo, Otredad, Razón crítica.

\footnotetext{
${ }^{1}$ (conequis@hotmail.com) Licenciado y maestro en sociología, por la UNAM. Doctor en Ciencia Política, por la UNAM. Autor de: (2017) El pensamiento político de Octavio Paz. Las trampas de la ideología, $2^{\mathrm{a}}$ ed. Universidad Nacional Autónoma de México / Universidad Pedagógica Nacional, México; (2001) Escritores y poder en México. La dualidad republicana, 1968-1994, FONCAConaculta / UPN, México; (2003) El poder frente a las letras. Vicisitudes republicanas (1994-2001), UPN, México. Su más reciente libro es: (2019) Poder en clave de sol. Una notación musical de lo político, México, Colofón.
}

ORCID: https://orcid.org/0000-0003-0003-2814. 


\begin{abstract}
Octavio Paz's critique over the meaning of modernity for Latin American countries, based on a poetic vision and a perspective granted for being an author from otherness, who postulated the need for Reason will recover his abandoned critical spirit from the attempt to imposing it as a hegemonic way of thinking about the present, past and future of all humanity, sent the basis for what we know today as theories of decoloniality. However, the reflection of the Mexican poet is ignored by the academic chapels that have thought about modernity, as by the thinkers who have assumed decolonialism as a way of imagining the future of our societies.

This paper presents several of Octavio Paz's contributions to the discussion, concluding that his work should be considered as a member of the genealogy of decolonial thinking.
\end{abstract}

Key-words: Octavio Paz, Modernity, Decolonialism, Otherness.

Desde su nacimiento, la modernidad es una pasión crítica y así es una doble negación, como crítica y como pasión (...) Pasión vertiginosa, pues culmina en la negación de sí misma: la modernidad es una suerte de autodestrucción creadora.

Octavio Paz ${ }^{2}$

\title{
Presentación
}

La propuesta es regresar a la obra ensayística de Octavio Paz para hacer una relectura de sus reflexiones sobre la modernidad a partir de las actuales discusiones sobre la decolonialidad, pues en esa faceta de su trabajo es posible encontrar algunas primeras bases firmes para construir una apreciación profundamente crítica sobre el sentido que la modernidad adquirió en Latinoamérica y, en consecuencia, de la manera en que habríamos de repensarla a partir de nuestras especificidades históricas, políticas y culturales. En otras palabras, Paz desde mediados del siglo pasado vislumbró la obligación intelectual de realizar la historización del concepto de modernidad y, en ese camino, abonó una crítica que, al rescatar la urgencia de pensarnos frente a ella recuperando nuestra propia historicidad, ayudó a cimentar el ulterior desarrollo de las teorías sobre el decolonialismo.

\footnotetext{
${ }^{2}$ Paz, Octavio, (1987) Los hijos del limo, México: Seix Barral, p. 20.
} 
El poeta mexicano fue de los primeros pensadores que identificó la necesidad de exigir a la Razón ser consecuente con su esencia crítica y, en esa medida, verse a sí misma en el espejo, lo cual llevaría a reconocer la historicidad de la modernidad y las razones por las cuales otras formas diferentes, distintas y diversas de pensar al mundo, al tiempo, al hombre, fueron desterradas a los confines donde habitan la ficción, la poesía, el mito, pero no la Razón objetiva y su hija, la ciencia. Desde esta perspectiva el nombre de Paz debería estar presente en la genealogía del pensamiento decolonial, cuestión que no sucede. $\mathrm{Su}$ voz no tuvo la caja de resonancia suficiente para ser escuchada dentro del discurso crítico sobre la modernidad, pero tampoco por los teóricos del decolonialismo. ¿A qué se debe ello? La respuesta no puede simplificarse a un ejercicio de ignorancia común, ya que si así fuera se tendría que explicar por qué solo uno de los ejes conformadores de una importante obra reconocida y galardonada por las más altas instituciones del establishment cultural mundial es prácticamente desconocida. La afirmación sobre el menosprecio a las aportaciones de Octavio Paz al análisis de la modernidad no se contradice por el hecho de que su obra haya recibido los premios literarios más importantes a nivel mundial, al contrario; ello enfatiza aún más el tufo discriminatorio sobre esa parte de su legado pues ni siquiera dichos laureles abonaron a la posibilidad de que sus reflexiones sobre la modernidad fueran tomadas en cuenta y referidas por los autores que han trabajado el tema. Más bien la explicación sobre ese silencio debe buscarse en el desdén con el que ambas capillas intelectuales ven a un pensamiento tan rico, sugerente y provocador como el suyo. A continuación, avanzaré algunas de las razones que esclarecen esa toma de distancia y segregación cultural y académica.

\section{Una crítica pionera}

Si bien poco a poco los trabajos de Octavio Paz sobre el significado de la modernidad para América Latina han ido siendo más conocidos, esa faceta de su reflexión crítica aun es la parte menos atendida de su obra en comparación con su trabajo poético y ensayístico de índole estética o política. No está de más recordar que su reflexión político social ha sido objeto de múltiples disputas y polémicas, y continúa siendo referencial para ciertos temas como la crítica a los que fueron los regímenes socialistas, al marxismo, o a la comprensión del funcionamiento del sistema político mexicano posrevolucionario. Así, el silencio sobre sus argumentaciones sobre la modernidad no deja de llamar la atención, pues su preocupación por explicarla y comprender cómo ella habría de ser pensada y reconsiderada desde México en particular y Latinoamérica en general, se desarrolla desde una fase muy temprana, alcanzado niveles 
de problematización más profundos que las elaboraciones de muchos de los teóricos de la modernidad reconocidos por la academia ${ }^{3}$.

Ya en sus escritos de los años sesenta, e incluso desde el Laberinto de la Soledad que suele datarse a finales de los cincuenta, es posible encontrar con toda claridad líneas argumentativas sobre la necesidad de identificar las características históricas, filosóficas, culturales y políticas por las cuales los dos conceptos fundamentales en los que se asienta la propuesta de la modernidad devinieron en nociones universales, es decir, constituyeron la narrativa que se impuso como única válida, legítima y posible del devenir de todo el planeta. Dichas nociones son: a) la Razón y, b) una percepción lineal del tiempo vinculada a la apreciación del futuro como sinónimo de progreso y desarrollo.

Esa resignificación crítica llevó a Paz a plantear la recuperación del sentido plural de la humanidad, el cual parecía haber pasado a un plano menor de importancia puesto que, desde la imposición de las nociones de progreso y desarrollo, se asignaba el rol de periferias subdesarrolladas a aquellas regiones que habían quedado en la retaguardia del ferrocarril de la modernidad, pareciendo estar condenadas a vivir fuera de la historia. El énfasis del poeta en el reconocimiento de la existencia de la otredad y, en particular, de la urgencia de repensar todo, absolutamente todo -empezando por el sentido de la modernidad y sus categorías definidores- desde nuestras propias perspectivas históricas, sociales, culturales, filosóficas, significó el inicio de una crítica precoz, vanguardista y radical a la modernidad.

Ya en otro texto he referido que Paz estaba consciente del desdén impuesto a esa faceta de su reflexión crítica y la molestia que el hecho le causaba ${ }^{4}$. En aquel trabajo avancé dos explicaciones a tal ninguneo. La primera es que dicho desarrollo intelectual había sido realizado por un poeta, esto es, por alguien que disertaba desde fuera de los límites que la Razón impone para legitimar cualquier aseveración, los cuales, obviamente, son los instituidos por la ciencia. Atreverse a desarrollar argumentos críticos distintos y contrapuestos al discurso avalado por la modernidad como el único capaz de conocer y aprehender a la realidad, sin atenerse a protocolos y metodologías legitimadas por la ciencia o (o peor aún, la Academia), fue cimentar las argumentaciones contemporáneas sobre el giro epistémico que constituye un atentado a la hegemonía de la Razón. Él era un poeta sí muy laureado, pero poeta al fin, y eso lo descalificó para ser tomado en serio por las cúpulas del establishment académico científico social.

${ }^{3}$ Blas Matamoro, "El ensayista Octavio Paz", en Santí, Enrico Mario, Comp. (2009), Luz espejeante. Octavio Paz ante la crítica, México: ERA. Él afirma: "Octavio Paz puede considerarse un precoz meditador, en el mundo hispánico, acerca de la crisis, tal vez final, de los tiempos modernos. Hoy, con la boga de la posmodernidad, ello es un tópico, pero, muy por el contrario, en las décadas del cincuenta y sesenta, pocos eran los que advertían que, paradójicamente, la modernidad se estaba anticuando.", p. 123.

${ }^{4}$ Cfr. Rodríguez Ledesma, Xavier, "El lunar del sol. La otredad de la historia”, en Vergara Gloria., comp. (2008) Visiones de Octavio Paz, México: Porrúa. 
Sin embargo, Paz sostuvo que el pensamiento poético constituye un sustrato fundamental para avanzar en la crítica del presente moderno a partir de la recuperación de la memoria pues ésta:

... es creadora y de ahí viene la paradoja de la poesía: la poesía es la memoria de los pueblos, pero también es aquella parte secreta del alma de cada uno, y del alma de los pueblos, en la cual esa zona, muy obscura y muy ambigua, refleja o, mejor dicho, perfila el futuro ${ }^{5}$.

La segunda razón para ser ignorado dentro del concierto crítico sobre la modernidad es aún más cruda pues se refiere a que Paz era un pensador no de las metrópolis sino de la periferia definida desde esos centros de poder, por lo cual él jamás habría sido reconocido como un interlocutor válido para disertar sobre tales afanes, máxime que su aportación se caracterizó por desmantelar las argumentaciones que sustentan su hegemonía al exponer la inequitativa relación de poder en la que se basa la imposición y universalización de una forma específica de concebir al mundo en detrimento de las otras múltiples posibilidades de hacerlo. Un poeta que desde las afueras de la modernidad ponía en picota las bases de la superioridad cultural (científica) y política (colonización) del discurso hegemónico impuesto por ella, no podía ser reconocido como par por aquellos para los que la modernidad y sus posibles reflexiones críticas se mueven dentro de ejes intelectuales bastante más simples y unidimensionales.

Ambos elementos (ser poeta y ser latinoamericano) explican la característica específica, profundamente crítica, de la reflexión paciana ya que ellos la proveyeron de la maleabilidad y toma de distancia necesarias para observar bajo otro lente a la modernidad, y comprender así que los diversos conceptos que ella impuso debían ser historizados, es decir, resignificados a partir de la esencia que la propia razón moderna enarbola como elemento axial: la crítica.

Dicha tarea, complicada en sí misma pues significa ser capaz de tomar distancia de una narrativa ya naturalizada e introyectada socialmente por su imposición con una antigüedad de por lo menos tres siglos, obliga a poner a la propia modernidad, a la Razón y a sus conceptos inherentes: progreso, desarrollo, crecimiento, objetividad, cientificidad junto a un largo etcétera, bajo una mirada que identifique la forma en que ese discurso se erigió como el único válido y legítimo a partir de la consolidación de relaciones de dominio bajo las cuales se discriminó al resto de filosofías, concepciones del mundo e historias, existentes en todas aquellas latitudes que conforman la otredad.

${ }_{5}$ Paz referido por Sheridan, Guillermo, (2015), Poeta con paisaje. Ensayos sobre la vida de Octavio Paz, T. 1., México: Era, p. 502.

Araucaria. Revista Iberoamericana de Filosofia, Política, Humanidades y Relaciones Internacionales, año $22, \mathrm{n}^{\circ} 43$. Primer semestre de 2020. Pp. 283-304. ISSN 1575-6823 e-ISSN 2340-2199 https://dx.doi.org/10.12795/araucaria.2020.i43.14 
La cultura moderna, colonial, se naturaliza, deviene invisible y, por ende, pasa desapercibida incluso para algunos pensadores que con buena voluntad se acercan a tratar de reconocer virtudes y atributos positivos en las expresiones culturales venidas desde fuera de las metrópolis. La vara para medir se asume acríticamente aplicándose para, en primer lugar, distinguir al "nosotros" metropolitano moderno del "ellos", esos otros que han surgido allá, en las periferias y los suburbios. A partir de esta base podemos comprender la soberbia detrás de reacciones como la reseñada por Leopoldo Zea cuando inquirió a un destacado pensador europeo (cuyo nombre se reserva) acerca del significado de que Paz hubiera recibido el Premio Nobel de Literatura en 1990:

“... ahora se elige a Octavio Paz, un cosmopolita”. “¿A uno de ustedes?”, le pregunté. "No", corrigió, "a uno como nosotros, no a uno de nosotros. De ser así se hubiera elegido a un Kundera, a un Havel o a algún otro candidato europeo ${ }^{6}$.

Tan petulante como discriminadora contestación muestra varias cosas. La primera es que, en efecto, por el simple hecho de ser un pensador externo a las metrópolis culturales, Paz, si bien podía ser reconocido por su legado, estaba impedido de ingresar con todos los honores a los elitistas salones eurooccidentales donde la Razón encarna, pues ellos son reservados exclusivamente para los nativos de las metrópolis. La segunda es positiva ya que sin pretenderlo constituye un reconocimiento implícito de que para los intelectuales de las metrópolis coloniales es prácticamente imposible visualizar una crítica como la de Paz sobre la modernidad, sazonada justamente por esa otra profundidad de campo que el vivir en las afueras provee. Es cierto, afortunadamente para el pensamiento crítico, el poeta no era uno de ellos, y justo por eso su reflexión fue capaz de visualizar con muchísima anticipación y de forma más rica un análisis que aquellos son incapaces de concebir. Por su condición "excéntrica", de mexicano, de latinoamericano, de habitante de los "suburbios de la cultura", de la "periferia", Octavio Paz vivió la otredad desde horizontes que le permitieron ahondar en el tema de la modernidad de una forma en que los habitantes de las metrópolis están imposibilitados histórica y culturalmente de hacerlo.

Ahora bien, es necesario reconocer que frente a ese tipo de afirmaciones podemos encontrar las de algunos pocos pensadores que sí son capaces de ubicar las razones por las que el análisis de Paz se caracterizó por un acercamiento diferente al eurooccidental respecto al tema de la modernidad. Es el caso del poeta francés Alain Bosquet quien con precisión distinguió que la crítica paciana abrevaba básicamente de dos fuentes: el surrealismo y "las costumbres del pensamiento autóctono mexicano"7.

${ }^{6}$ Zea, Leopoldo, “Paz: a lo universal por lo profundo.”, en Santí, E. M., op.cit., p.52.

7 “(...) tendremos que esperar hasta la Segunda Guerra Mundial para contemplar la ósmosis entre 
En ese mismo orden es posible ubicar también el estudio de Jaques Lafaye dedicado precisamente a la forma en que el poeta mexicano analizó la modernidad. Este autor sí identifica el hecho excepcional de que un poeta haya sido también un analista social cuyas reflexiones se destacan por haber llevado la retórica de la otredad al abordaje del sentido de la modernidad para las civilizaciones amerindias, con lo cual el sentido histórico tradicional vinculado a las historiografías modernas estalla por los aires. Así, acertadamente concluye que: a) el surrealismo, b) el pensamiento autóctono mexicano (aun con la imprecisión que el concepto tiene en sí mismo), y, c) un razonamiento caracterizado por su autonomía frente a los estancos disciplinares (epistemológicos) instituidos por la propia Razón moderna, constituyeron los cimientos que aportaron a Paz la flexibilidad y maleabilidad analítica requerida para ser capaz de poner a la Razón y sus consecuencias, bajo el lente de la crítica que tiene en el reconocimiento del otro su eje fundamental ${ }^{8}$. Sin embargo, si bien el filósofo francés es sensible en el reconocimiento de las bases de la reflexión paciana sobre la modernidad, es incapaz de eludir las modernas ansias taxonómicas por encasillar a un pensamiento rebelde a la clasificación. Para Lafaye la filosofía de Paz fue una poética y toda su obra sobre el yo, el otro y el mundo real e imaginario es un extenso, polifacético, pero unitario ensayo 9 .

"Poética" y "ensayo". El primero, un concepto al que se le niega la posibilidad de la objetividad científica que garantizaría acceder a una explicación "objetiva" de los hechos basada más en datos concretos ("duros") y protocolos precisos. El segundo, una forma de escritura a la que tradicionalmente se le ha regateado su reconocimiento en términos de acercamientos riguroso y especializado a los temas que se aborden. Mientras la poética habita los mismos espacios adonde se exilia a la ficción, los mitos y la fantasía, el ensayo -nos dicen- es una forma sugerente pero no rigurosa de abordar los temas elegidos ${ }^{10}$.

Quizá Lafaye, en lugar de dar rienda suelta a los espíritus catalogadores, debió recuperar una sensibilidad como la expresada por María Zambrano para

el surrealismo y las costumbres del pensamiento autóctono americano. (...) Fue entonces que se consumó ese tórrido matrimonio y así una vieja tradición reencontró allí un prejuicio moderno y un impulso natural vino a injertarse en una determinación tenaz. A nadie más que al poeta mexicano Octavio Paz corresponde la responsabilidad histórica de este encuentro, el cual de manera plenamente adecuada ocurrió en los años cincuenta, una época propicia para este tipo de síntesis.", Bosquet, Alain, "Octavio Paz o el surrealismo telúrico", en, Santi, E.M., Op.cit., p.273.

8 "Paz se pasa de la erótica a la política, de la poesía a la religión, de la historia a la psicología, en virtud de su sistema "de vasos comunicantes", como lo llamaba él mismo. En realidad, lo que nos propone es una sophia, una sabiduría de la vida y el mundo. Al articular al amor con la persona y la libertad, es decir, al reconocer al otro, Paz lo constituye en el eje de la civilización." Lafaye, Jaques, (2013) Octavio Paz en la deriva de la modernidad, México: FCE, p.192.

${ }_{9}$ Ibidem, p.229.

10 En contraste al ánimo esquemático clasificatorio de Lafaye, Julio Cortázar -escritor y latinoamericano al igual que Paz- escribió que su amigo mexicano tenía: “... el poder de hacer coexistir paralelamente y sin choques (...) el canto poético y la reflexión analítica.”, en, Santí, E. M., op. cit., p 17.

Araucaria. Revista Iberoamericana de Filosofia, Política, Humanidades y Relaciones Internacionales, año $22, \mathrm{n}^{\circ} 43$. Primer semestre de 2020. Pp. 283-304. ISSN 1575-6823 e-ISSN 2340-2199 https://dx.doi.org/10.12795/araucaria.2020.i43.14 
quien una de las características de la obra de Paz era: "saber tratar con "lo otro", con lo heterogéneo. Con "lo otro" de la razón y que no por ello deja de constituir lo real"11.

Si Paz es ignorado por los autores referenciales eurooccidentales para el estudio de la modernidad, sus aportaciones al tema son reconocidas por los estudiosos y conocedores a profundidad de la obra del poeta mexicano, quienes han identificado la importancia de esa faceta de su obra y han intentado, aunque con poco éxito, que ella tenga mayor trascendencia en la discusión contemporánea al respecto. Gabriel Zaid, miembro distinguido del grupo cultural que encabezó $\mathrm{Paz}$, ha escrito párrafos contundentes y certeros reclamando la atención y el reconocimiento que éste, junto con otros intelectuales iberoamericanos, debieran tener en las discusiones contemporáneas sobre la cultura occidental:

\begin{abstract}
... escritores como José Ortega y Gasset o como Octavio Paz, que se meten con la cultura occidental, que la replantean, que la critican, que pretenden cambiar el curso de la conversación, modificar la agenda, interrumpir como participantes, no como tema de la interrupción, exigen un segundo reconocimiento: voz y voto, no sólo admiración. No basta con reconocerlos como grandes artistas de la prosa, ni siquiera como creadores de una prosa que no existía en español: lo que hacía falta para pensar por nuestra cuenta y en nuestra lengua la cultura moderna. El género que practican obliga a reconocerlos también como líderes intelectuales, a reconocer que pesan en la conversación occidental. Sucede más difícilmente ${ }^{12}$.
\end{abstract}

Líneas antes al párrafo citado, Zaid había sumado el nombre de Jorge Luis Borges como uno de los interlocutores que, apropiándose de la literatura universal para transformarla, han ampliado la conversación llamada universal consiguiendo volver menos provincianos no a los latinoamericanos sino a los europeos.

María Zambrano, Leopoldo Zea, Julio Cortázar, Gabriel Zaid, autores referidos aquí cuya sensibilidad les permite identificar la importancia de la reflexión paciana sobre la modernidad. ¿Qué los une a ellos con Jorge Luis Borges, Ortega y Gasset y el propio Paz? Simple, que todos son pensadores surgidos en los suburbios de la modernidad pues, a pesar de los denodados esfuerzos de la intelectualidad ibérica de ser considerada como miembro de las grandes metrópolis culturales hegemónicas, ella no deja ser vista como integrante de aquella parte de Europa que no logró alcanzar los niveles de desarrollo cultural (ni económico) que le permita ser reconocida como tal. Así, España y Portugal -junto a otras nacionesconstituyen las "periferias europeas", cuestión para nada del agrado de esas élites culturales autóctonas ${ }^{13}$.

${ }^{11}$ Zambrano, María, "Un descenso a los infiernos", en, Santí, E. M., op. cit., p. 22-23.

${ }_{12}$ Zaid, Gabriel, "La emancipación cultural", en Santí, E. M., op. cit., 49-50.

${ }^{13} \mathrm{Al}$ respecto Zaid contundente concluye: "Aunque la cultura hispánica fue protagonista de la 
Con todo lo anterior es posible comprender las causas del desconocimiento y negación por parte de los estudiosos de la modernidad de la obra y las aportaciones al tema de un poeta latinoamericano que, además, no aceptó pensar desde dentro de los esquemas y las formas instauradas por los cánones modernos. Sin embargo, ello no debería ser obstáculo (al contrario) para que fuera recuperada y utilizada por los teóricos de la decolonialidad que, justamente, tiene como una de sus bases rectoras la necesidad de historizar los mecanismos a través de los cuales la modernidad instauró como válida y legítima a ciertas, y solo ciertas, formas de acercarse al estudio y comprensión de los temas sociales y de la realidad toda. A pesar de eso, la obra de Paz tampoco ha sido reconocida y utilizada dentro de las argumentaciones y teorizaciones sobre la decolonialidad y otras problematizaciones que corren en paralelo ${ }^{14}$.

Si bien ambos argumentos (ser poeta y provenir de los "suburbios de la civilización") ayudan a comprender las razones por las que la obra de Octavio Paz no ha sido considerada como fuente significativa dentro de la discusión sobre la modernidad, ellos no son suficientes para explicar por qué tampoco ella es conocida ni tomada en cuenta por los actuales desarrollos teóricos sobre el decolonialismo. Esta indiferencia se debe, creo, a las posiciones políticas del poeta. Me refiero en particular a su crítica al marxismo y al socialismo realizada justo cuando ese tipo de análisis eran prácticamente considerados como traiciones políticas que lo único que lograban era hacerles el juego a los enemigos de la utopía. Paz, es de sobra conocido, fue un pensador que no se adscribió a las corrientes críticas de izquierda que lo identificaban como un antagonista, cuando no un enemigo, cuya obra debía ser combatida o desdeñada en su totalidad. Luego entonces, sus deliberaciones parecieran continuar siendo tabú para esa parte del pensamiento crítico de izquierda aglutinado hoy en día alrededor de la decolonialidad.

Ese silencio, ese ejercicio de los teóricos decoloniales de ignorar una crítica a la modernidad venida desde la otredad poética y geográfica, no es generalizado sino discrecional. La prueba radica en la recuperación totémica del pensamiento de un poeta caribeño como el de Aimé Césaire, quien en cuatros pequeños texto aportó elementos sustanciales para abrir avenidas reflexivas sobre el tema. Los estudiosos del decolonialismo han hecho suya la contribución analítica del poeta haitiano; en contraste, jamás refieren alguna de las innumerables aportaciones que Paz hizo a la problematización y crítica de la civilización occidental en la que las coincidencias cronológicas y temáticas

cultura occidental, acabó en su periferia, como las ruinas de un pasado bárbaro, de tractivo romántico, pero nada más. Dejó de recibir la atención que se presta a un interlocutor para recibir la que se presta a un tema. La conversación quedó de espaldas a la cultura hispánica, ya no se diga a la inteligencia americana. En cambio, la apertura de la inteligencia americana a la cultura universal ha estado siempre viva: ...", Ibidem, p.50.

${ }^{14}$ Solo Enrique Dussel en Política de la liberación. Historia mundial y crítica menciona escuetamente a El laberinto de la soledad y Posdata.

Araucaria. Revista Iberoamericana de Filosofia, Política, Humanidades y Relaciones Internacionales, año $22, \mathrm{n}^{\circ} 43$. Primer semestre de 2020. Pp. 283-304. ISSN 1575-6823 e-ISSN 2340-2199 https://dx.doi.org/10.12795/araucaria.2020.i43.14 
con los argumentos esgrimidos por Césaire son evidentes. Ironías del quehacer intelectual, el decolonialismo reprocha que a causa de la discriminación la obra del haitiano no sea valorada como par de los desarrollos teóricos realizados en los centros coloniales, sino que, en el mejor de los casos, se le voltee a ver como un simple objeto que llama la atención para ser estudiado, pero no asumido ${ }^{15}$; pero en sus disertaciones esos mismos indignados ni siquiera mencionan la voluminosa obra del mexicano.

En ese mismo sentido es posible ubicar la invisibilidad de las aportaciones de Octavio Paz en las fuentes utilizadas por Boaventura Dos Santos en su trabajos sobre las epistemologías del sur, esto es, el desarrollo teórico acerca de la necesidad de asumir la historicidad de los regímenes de verdad impuestos por la modernidad y, en consecuencia, la obligación de recuperar las diversas formas de concebir al mundo, conocerlo y aprehenderlo de las culturas constitutivas de la otredad; todo ello como un acto de resistencia política frente a la histórica imposición colonial. La lista de autores utilizados por el sociólogo portugués es amplia y, si bien ahí aparecen varios pensadores iberoamericanos, el nombre del poeta mexicano brilla notoriamente por su ausencia ${ }^{16}$.

El desarrollo de la teoría de la decolonialidad y de las epistemologías del sur son solo dos muestras de la manera en que, para las actuales críticas radicales a la modernidad englobadas en el decolonialismo, la obra de Paz es absolutamente irrelevante o desconocida. Las razones - ya lo señalé más arribason de carácter eminentemente ideológico-político. Señalar que dicha exclusión se debe a que la crítica del poeta se queda dentro de los ejes establecidos por la modernidad y, por ende, no coadyuva a trastocar los paradigmas dominantes no es correcto, según veremos a continuación veremos a continuación.

Revisemos algunas de las similitudes entre la perspectiva crítica paciana y los razonamientos de Césaire que guían la propuesta decolonial. Elijo hacerlo entre ambos autores en virtud de que los dos son poetas nacidos en la otredad. Las fuentes en las que me baso para acercarme a la reflexión del haitiano son los cuatro textos centrales en las que él desarrolló las argumentaciones que a la sazón constituyeron algunas de las bases del decolonialismo. Ellos son: "Discurso sobre la colonialidad", "Cultura y colonización", "Carta a Maurice Thorez" y "Discurso sobre la negritud. Negritud, etnicidad y culturas afroamericanas".

15 “... a pesar de la contribución de Césaire al cambio de terreno epistémico que estamos analizando, su pensamiento es hoy reconocido pero considerado marginal en relación con la historia del pensamiento de los hombres blancos. Un pensamiento para ser «estudiado», pero no para ponerlo en la misma mesa que Carl Schmitt, Alain Badiou o Richard Rorty.", Mignolo, Walter D., "El giro gnoseológico decolonial: la contribución de Aimé Césaire a la geopolítica y la corpo-política del conocimiento", en, Césaire, Aimé, (2006), Discurso sobre colonialismo (1955), España: Akal. p.199.

${ }^{16}$ Cfr. a) De Sousa, B. (2009), Una epistemología del sur, México: CLACSO /Siglo XXI, y b) De Sousa, B (2013), Descolonizar el saber, reinventar el poder, Chile: TRILCE. 


\section{Gestando las teorías de la decolonialidad. Poesía, otredad y crítica}

Aimé Césaire y Octavio Paz eran poetas. El primero nació en 1913 en Haití; el segundo vio la luz apenas un año después en México. Césaire vivió una doble exclusión producida por la imposición colonial: ser originario de una nación pobre de los suburbios de la modernidad y, además, ser negro, con todo el significado discriminatorio (cultural, político, económico) característico de la negritud. Paz, por su parte, atestiguó el sometimiento y la asimilación cultural de algunas de las grandes civilizaciones de la historia (las de origen desarrolladas en su país de nacimiento y, posteriormente, la hindú) a la imposición de una sola noción civilizatoria, la de la modernidad.modernidad. Curiosamente ambos pasaron parte de su vida en el París de la posguerra donde se acercaron al movimiento surrealista. Césaire escribió en 1950 su Discurso sobre el colonialismo, texto que a la sazón devendría en uno de los documentos fundacionales de las reflexiones decoloniales. Paz publicó El Laberinto de la soledad también en $1950 \mathrm{y}$, si bien en algunos escritos previos es posible encontrar ya algunos acercamientos a la crítica de la modernidad, fue en ese emblemático libro donde quedó asentado el tema que constituiría uno de los ejes de su reflexión política. Sus disertaciones al respecto alcanzaron sus niveles más profundos principalmente en: Corriente alterna (1967), Los signos en rotación (1971), Los hijos del limo (1972) y, finalmente, en su Vislumbres de la India (1995).

Ambos, desde sus especificidades históricas, sociales y culturales, coincidieron en visualizar que el problema de la modernidad radicaba en que ella era una construcción histórica cuya característica definitoria consistía en asumirse de forma acrítica (deshistorizada) como la única posibilidad de desarrollo para el mundo entero. Frente a ello, los dos poetas empezaron a construir cada uno por separado una respuesta basada en la necesidad de historizar a la modernidad y, en consecuencia, la urgencia de reconocer y recuperar la riqueza cultural de todas aquellas civilizaciones que ésta había subsumido, negado o pretendido erradicar. Revisemos algunas de sus argumentaciones y la forma en que en ellas se comparten preocupaciones y perspectivas críticas. Empecemos por el poeta caribeño.

Césaire en su "Discurso sobre la colonialidad" comienza planteando una incendiaria hipótesis referida a que el repudio europeo a Hitler se debe a una razón muy sencilla: haber aplicado al interior de Europa procedimientos colonialistas como los que ese continente impuso en otras regiones del mundo (Medio Oriente, África y la India). Después de ubicar este provocador marco inicial, su argumentación deriva hacia los vínculos entre los procesos coloniales de comprender al mundo y la imposición en todos los países colonizados de ciertos conceptos como "progreso y "desarrollo", en detrimento o franca 
eliminación de otras posibilidades. De cara a esa terrible realidad, él confesaba que: “... mi único consuelo es que las colonizaciones pasan, que las naciones sólo dormitan un tiempo y que los pueblos permanecen"17.

Para Césaire el progreso impuesto por la modernidad no se refiere al mejoramiento del nivel de vida de los habitantes, al contrario, implica arrasar con la familia y los vínculos políticos, sociales y culturales tradicionales, esto es, el progreso lleva ineludiblemente a la pulverización de la estructura social y económica de las comunidades. Mientras que los europeos lo refieren como un estadio donde se ha podido crear la cura de algunas enfermedades y se plantea el posible acceso a niveles de vida superiores a los que actualmente tienen, para los países colonizados ese concepto significa: "sociedades vaciadas de ellas mismas, de culturas pisoteadas, de instituciones minadas, de tierras confiscadas, de religiones asesinadas, de magnificencias artísticas aniquiladas, de extraordinarias posibilidades suprimidas" 18 .

A la antigua injusticia -continúa- la Europa colonizadora le ha sumado el abuso y la discriminación moderna. Si bien es imposible imaginar cómo se habrían desarrollado aquellas naciones sobre las que Europa impuso la modernidad, es preciso crear una sociedad nueva enriquecida por la potencia productiva moderna, pero con la calidez que solo la fraternidad antigua podría proporcionar. Fraternidad, categoría axial para la convivencia humana en cuya necesidad de recuperarla con urgencia coincidirá más tarde Paz ${ }^{19}$. Fraternidad, concepto básico enarbolado por la revolución francesa, pero olvidado por la colonización.

A partir de que los europeos impusieron su concepción del mundo, su modelo de desarrollo al resto del planeta, ellos -afirma Césaire- pretenden tener la superioridad científica, moral y religiosa, por lo que Occidente se ha asumido como el sujeto capaz de hacer la etnografía de los otros y, de ninguna forma, que los otros hagan la etnografía de Occidente. Es decir, desde la cultura hegemónica eurooccidental se busca comprender a los otros, esos otros son quienes deben ser estudiados con las metodologías modernas definidas por las epistemologías occidentales para desde ahí integrarlos a la narrativa unidimensional y unívoca de la colonización.

En "Cultura y colonización" Césaire da un paso más al ubicar con precisión que la colonización es la imposición de la lógica del capitalismo:

... a los ojos del mundo, la gran revolución que encarna Europa en la historia de la humanidad está constituida, no por la introducción de un sistema fundado

\footnotetext{
${ }^{17}$ Césarie, A., op.cit., p. 21.

18 Ibidem, p. 20.

19 "La fraternidad es el valor que nos hace falta, el eje de una sociedad mejor. Nuestra obligación es redescubrirla y ejercitarla.”, Paz, Octavio, (1993) Itinerario, México, Fondo de Cultura Económica, p.194.
}

Araucaria. Revista Iberoamericana de Filosofia, Politica, Humanidades y Relaciones Internacionales, año $22, \mathrm{n}^{\circ} 43$. Primer semestre de 2020. Pp. 283-304. ISSN 1575-6823 e-ISSN 2340-2199 https://dx.doi.org/10.12795/araucaria.2020.i43.14 
en el respeto de la dignidad humana, como se encarnizan en hacérnoslo creer, ni por la invención del rigor intelectual, sino por un tipo de consideración bien distinta que sería desleal no encarar: saber que Europa ha sido la primera en inventar e introducir, en todos los lugares en que ha dominado, un sistema económico y social fundado en el dinero, y en haber eliminado despiadadamente todo, y digo todo, cultura, filosofía, religiones, todo lo que podía retrasar o paralizar la marcha bacia el enriquecimiento de un grupo de hombres y pueblos privilegiados ${ }^{20}$.

En todas partes donde la colonización irrumpe las civilizaciones nativas se marchitan produciéndose una especie de subcultura condenada a permanecer marginal u monopolizada por ciertas élites, por lo que las masas y la cultura popular no pueden desarrollarse como cultura verdadera. Esta idea del autor haitiano es central pues contiene la explicación del porqué las expresiones culturales (concepciones del mundo, del tiempo, historiografías, epistemologías, etc.) de las civilizaciones y grupos sociales originarios son condenadas a representar un papel subalterno, accesorio, frente a las impuestas por la modernidad, siendo arrojadas al lugar donde habita la ficción, el mito, la magia, la poesía, el folclor y demás categorías referidas a cuestiones no modernas, científicas, racionales, objetivas, etcétera.

En los textos revisados de Césaire aparece una disertación más que coincide completamente con la lectura histórica realizada por Octavio Paz. Ella es la precisión con la que el haitiano identificó que la crítica a la modernidad (implícita en su análisis del colonialismo) llevaba al cuestionamiento no solamente de las bases filosóficas y culturales del capitalismo, sino que, al asumir a la modernidad como esa forma filosófica que impone una noción del tiempo unilineal en la que el futuro se iguala al progreso, ella involucraba también a las propuestas socialistas. Césaire estableció que la vinculación cultural entre colonialismo y socialismo era tan innegable que la militancia comunista asumía una lectura de la otredad absolutamente moderna; por ello es que la lucha de los pueblos colonizados pasaba por marcar distancia de concepciones como las del Partido Comunista Francés (PCF) caracterizadas por:

su asimilacionismo inveterado; su chovinismo inconsciente; su convicción apenas primaria -que comparten con los burgueses europeos-de la superioridad omnilateral de Occidente; su creencia en que la evolución tal como se ha desarrollado en Europa es la única posible; la única deseable; aquella por la cual el mundo entero deberá pasar; para decirlo todo, su creencia, raramente confesada pero real, en la Civilización con mayúscula; en el Progreso con mayúscula (como muestra su hostilidad frente a lo que llaman con desdén el "relativismo cultural" (...) Debe decirse, de paso, que los comunistas franceses tuvieron una buena escuela. La de Stalin. Y Stalin es, indiscutiblemente, aquel

${ }^{20}$ Césaire, A., Op.cit., p. 51.

Araucaria. Revista Iberoamericana de Filosofia, Política, Humanidades y Relaciones Internacionales, año $22, \mathrm{n}^{\circ} 43$. Primer semestre de 2020. Pp. 283-304. ISSN 1575-6823 e-ISSN 2340-2199 https://dx.doi.org/10.12795/araucaria.2020.i43.14 
que reintrodujo en el pensamiento socialista la noción de pueblos "avanzados" y de pueblos "atrasados" 21.

El que Césaire en octubre de 1956 enfrentara así a Maurice Thorez, líder del PCF no es casual. Recordemos que apenas en febrero de ese año se había realizado el XX Congreso del Partido Comunista de la Unión Soviética (PCUS) que marcó el inicio del deslinde crítico dentro del propio régimen soviético frente al estalinismo, con lo cual el camino de la crítica se despejó un poco siendo aprovechado a cabalidad por el poeta caribeño que se lanzó de frente contra el partido galo. Además, para el caso específico que interesa a este trabajo, Césaire señalaba puntualmente el espíritu colonial del socialismo propuesto por esas instituciones políticas caracterizado por el exterminio absoluto de cualquier posibilidad del ejercicio de la crítica.

De tal forma, concluía, por más que le pesara a los esquemas socialistas vigentes en aquella época, la lucha de los negros no era la lucha de los obreros franceses, pues aquellos se baten contra el capitalismo colonial y el racismo, mientras que el proletariado francés solo lo hacía contra un capitalismo de características metropolitanas. Quedaba claro así la superación del sentido de la negritud no pasaba por el derrocamiento del sistema burgués y la consecuente construcción del socialismo, pues éste al final de las cuentas parte de las mismas bases teóricas culturales modernas de visualizar el futuro, es decir, el tiempo.

Del "Discurso sobre la negritud" finalmente me interesa destacar una idea: el enarbolamiento que Césaire hace de la especificidad cultural y social del ser negro como una comunidad reconocida históricamente que, habiendo sufrido opresión y exclusión no deja de resistir, por lo que justamente una estrategia central de esa batalla es el reconocimiento de que ninguna doctrina social sería válida mientras no fuera repensada por y para nosotros, y convertida a nosotros ${ }^{22}$.

Sintetizando el apresurado resumen de la crítica de Aimé Césaire al colonialismo resaltan las siguientes ideas:

- La modernidad es una invención europea que se ha impuesto al resto del planeta.

- Progreso y desarrollo son nociones vinculadas a una, y solo una, forma entender la historia.

- El progreso, como sinónimo de futuro, se refiere fundamentalmente a cuestiones de índole económica que dejan de lado el resto de los ámbitos de expresión y vivencia de la humanidad. En esa perspectiva la modernidad

${ }^{21}$ Ibidem, p. 81.

${ }_{22}$ Césaire concluía: “...es necesario imponer una verdadera revolución copernicana: tan enraizada está en Europa, y en todos los partidos, y en todos los dominios, desde la extrema derecha basta la extrema izquierda, la costumbre de hacer por nosotros, la costumbre de disponer por nosotros, la costumbre de pensar por nosotros, en resumen, la costumbre de cuestionarnos este derecho a la iniciativa (...) que es, en definitiva, el derecho a la personalidad”, Ibidem, p. 82. 
llevará ineludiblemente a la destrucción de la naturaleza, esto es, al fin del mundo tal como lo conocemos.

- La modernidad es la imposición del capitalismo, pero ella también contempla las bases filosóficas que sustentan al socialismo. Por ello la crítica de la modernidad pasa por hacer la crítica del estalinismo y las concepciones del socialismo surgidas bajo a su cobijo.

- Los diversos grupos sociales negados, discriminados y reprimidos por la modernidad deben buscar sus propias formas de mirarse frente a ella, lo cual requiere el reconocimiento de su propia existencia y de la legitimidad de sus especificidades culturales, filosóficas, políticas económicas.

Estas veredas críticas de Césaire devinieron en sustrato de las actuales propuestas decoloniales. Frente a ello cabe rescatar la pregunta rectora de estas páginas acerca de las razones por las que la amplia obra de Octavio Paz, en la que disertó incluso con mayor profundidad que la del poeta haitiano sobre ideas similares, son ignoradas dentro del discurso decolonizador. Miremos un poco a qué nos referimos.

Ya señalé que desde muy temprano Paz comenzó a cuestionarse sobre la forma en nuestra región se había asumido la modernidad pues desde 1941 avanzó la idea de que Latinoamérica era su hija bastarda. Sin embargo, fue en El laberinto de la soledad (1950) donde el tema aparece ya con bastante claridad. En él Paz llega a la conclusión de que las sociedades mexicana -en particular- y la latinoamericana -en general- no son modernas ya que difícilmente podría afirmarse que a nivel político imperaran la libertad y la democracia, conceptos que, junto al desarrollo económico, constituyen las características fundamentales de dicho estadio ${ }^{23}$. La reflexión ahí iniciada se afilaría aún más en los siguientes lustros.

Para mediados de la década de los sesenta Paz tenía perfectamente clara que la idea del progreso conllevaba la instauración de una sola forma de concebir al tiempo, por lo que cuestionar y superar esta imposición cultural era sentar las bases para la recuperación política, cultural y filosófica de las culturas constitutivas de la otredad, categoría ésta que, en sus propias palabras, habría de considerarse definida por la originalidad y el aislamiento ${ }^{24}$. Él fue contundente, frente a la hegemonía de la concepción lineal del tiempo era necesario reconocer que "estamos ante una pluralidad de tiempos históricos" 25 .

${ }^{23}$ Cfr. Rodríguez, Ledesma, Xavier (1996), El pensamiento político de Octavio Paz. Las trampas de la ideología, México: UNAM / Plaza y Valdés, p. 429 ss.

24 "Originalidad es sinónimo de otredad y ambas de aislamiento. Las civilizaciones americanas (precolombinas) jamás conocieron algo que fue una experiencias repetida y constante de las sociedades del Viejo Mundo: la presencia del otro, la intrusión de las civilizaciones y pueblos extraños.

(...) He mencionado como rasgos constitutivos de la civilización mesoamericana: la originalidad, el aislamiento y lo que no he tenido más remedio que llamar la otredad.”, Paz, en Lafaye, J., Op.cit., pp. 212-213

25 "Un escritor incómodo" (Entrevista a Danubio Torres Fierro, 1991), en, Paz, Octavio, (2003) 
Comprender la riqueza que el concepto de otredad posee como elemento explicativo de la modernidad solo podía ser un atributo del pensamiento surgido de esos espacios originales y aislados. Paz lo sabía y lo reconocía: "Mi primera noción de la existencia de otras civilizaciones, aparte de la occidental, se la debo a México, al lugar donde nací. Soy otro por nacimiento"26.

Ubicar desde la otredad posibles vías de desarrollo propias llevaría a la revalorización y consiguiente recuperación de las filosofías y culturales originarias, dentro de las cuales la noción del tiempo es un elemento fundamental. Hacerlo es recuperar el sentido de pluralidad, ejercer la libertad de ser diferentes, revalorar y legitimar las cosmovisiones características a la otredad. Historizar la forma en que se nos ha imbuido una y solo una noción de tiempo como la única posible es avanzar en su visibilización, lo cual constituye el primer paso para empezar a romperla a fin de hacerla volar por los aires en aras de recuperar nuestros tiempos y construir nuestros propios relojes. Paz lo escribía claramente: "Decir que el tiempo rectilíneo se acaba no es una herejía intelectual ni delata una culpable nostalgia por el mito y sus ciclos fatales y sangrientos. El tiempo cambia de forma y con él nuestra visión del mundo, nuestras concepciones intelectuales, el arte y la política" ${ }^{27}$.

Junto con la noción lineal de tiempo, la imposición de la Razón como la forma universal para aprehender y conocer al mundo es otra de las bases de la modernidad. Dicha aspiración por comprender se traicionó a sí misma al implantarse sobre todo el mundo, eliminando de facto la posibilidad de validación y legitimación de otras formas de conocer y vincularse con la naturaleza, la sociedad y los misterios de sus funcionamientos. Esa imposición se sustentó en la renuncia al ejercicio de la crítica, cuestión que la propia Razón postulaba como su elemento distintivo. La Razón se negó a verse a sí misma en el espejo y, al repudiar su historicidad, abjuró de su pasión por la crítica.

Según el poeta mexicano una de las claves para comprender la contradicción inherente al el encumbramiento realizado por la modernidad de ideales como la libertad, la crítica, la fraternidad, fue su esfuerzo por imponer sus valores, aspiraciones y metas como las únicas legítimas que, por lo mismo, debían hacerse hegemónicas en todas las latitudes. Ello significó olvidarse de la crítica, renunciar a ella, hacerla desaparecer. Fue desvanecer sus propios postulados básicos en aras de implantar urbi et orbi una noción específica y excluyente del tiempo, lo que solo pudo llevarse a cabo con su desistimiento a ejercer la razón crítica. La crítica, pasión y razón de ser de todo el pensamiento moderno, eludió ser consecuente consigo misma, evadió aplicarse lo que postula como base fundamental de la Razón. Identificar y hacer visible esa contradicción, esa

\footnotetext{
Obras Completas (OC), T.15. México: Fondo de Cultura Económica, p.237.

26 "Poesía, pintura, música, etcétera." (Entrevista de Manuel Ulacia), en Paz. O., OC.15, Op.cit., p.124.

27 Paz Octavio, (1983) Los signos en rotación y otros ensayos, Alianza, España, p.285.
} 
traición a la pasión crítica, como lo hizo Paz fue un proyectil al corazón de la narrativa sobre la legitimidad y superioridad del discurso moderno.

Ahora bien, cuando la crítica - de la que la Razón ha abjurado en aras de consolidar su compromiso político con los afanes colonialistas de la modernidades ejercida desde la otredad, el pensamiento eurooccidental se incomoda, sorprende y trata de evadirla minimizándola, negándola, discriminándola, escatimándole legitimidad. Quizá este sea uno de los elementos por los cuales Octavio Paz también marcaba una tajante distancia con las formas y fondos de la vida académica y de las capillas que habitan los campus universitarios, pues la Razón institucionalizada bajo los ropajes academicistas constituye un ejemplo muy claro de los afanes impositivos modernos vinculados al monopolio del logro legítimo de la objetividad y la verdad a través de algunos métodos y protocolos que se avalan a sí mismos, y que son los que envían al submundo de la ficción y la poética a cualquier otro tipo de explicación y saber característico de la otredad.

Otro punto común entre los argumentos pacianos y las reflexiones críticas de Aimé Césaire sobre la modernidad es el señalamiento de que el marxismo y el socialismo son filosofías y propuestas políticas que comparten la concepción lineal del tiempo donde el futuro es sinónimo de progreso. De ahí que la propuesta de la revolución socialista no sea otra cosa que la aspiración a llevar el desarrollo a un nivel, si bien distinto al capitalista en términos del planteamiento sobre el reparto social de la riqueza producida, idéntico en la forma de concebir el futuro prometido: sometimiento y triunfo sobre la naturaleza, etcétera. Uno de los elementos nodales de la crítica pacista a las propuestas del socialismo y del marxismo radicaba justamente en señalar que un pensamiento crítico como el planteado por Marx, al ubicar la necesidad e inevitabilidad de la revolución mundial perdía los matices de la especificidad, desvaneciéndose así la posibilidad de imaginar otras vías de desarrollo diferente a la moderna. La idea del progreso era una ideología compartida por las filosofías modernas, la socialista incluida.

Pero la crítica de Paz al socialismo no se detuvo ahí. Si en los años cincuenta del siglo pasado Césaire se enfrentó al estalinismo cosmopolita del Partido Comunista Francés, en esa misma época el mexicano confirmó su alejamiento de la izquierda cuando hizo suya la denuncia de la existencia de campos de concentración en la Unión Soviética. Esa toma de distancia rápidamente se transformó en una disputa con los movimientos socialistas a partir de su señalamiento de que el pensamiento había renunciado a las propuestas básicas de democracia y fraternidad que caracterizaban al ideal socialista. Dicha querella se mantuvo hasta sus últimos años de vida, cuando el poeta reconoció que el ideal socialista, alejado y contrario a lo que había sucedido dentro de los países del socialismo realmente existente, era una opción humanista que valía 
la pena seguir teniendo presente pues encarnaba una posibilidad de reencontrar el sentido de fraternidad perdido durante el periplo de la modernidad.

Para Paz, a inicios de los años ochenta, era necesario avanzar sin dilación en la construcción de un pensamiento crítico que revalorara y recuperara las filosofías, concepciones del mundo y saberes de las civilizaciones que constituyen la otredad, como única forma de evitar el fin del mundo al que la modernidad parecía encaminarnos. Contundente señalaba:

... es indispensable la presencia de una imaginación activa y enraizada en la tierra mental nativa: soñar y obrar en términos de la realidad propia. ¿Cómo es posible que esos pueblos, creadores de conjuntos arquitectónicos que fueron asimismo centros de convivencia humana, puntos convergentes de la imaginación y la acción práctica, las pasiones y la contemplación, el placer y la política -esos pueblos que hicieron del jardín un espejo de la geometría, del templo una escultura palpitante de símbolos, del sonar del agua en la piedra un lenguaje rival de los pájaros- cómo es posible que hayan renegado a tal punto de su historia y de su vocación? ${ }^{28}$.

Luego entonces, constituía una tarea política primordial tomar distancia de las concepciones eurooccidentales para poder repensarnos a nosotros mismos y así recuperar nuestras propias concepciones del tiempo, alejadas y diferentes a las de la modernidad, ello en aras de recuperar la armonía arrasada durante la frenética carrera por alcanzar el futuro a la cual nos hemos visto arrastrados desde hace cinco siglos. En ese andar el pensamiento poético era fundamental:

Hemos dicho que una de sus funciones (de la poesía) podría ser la vuelta a los orígenes, al hombre anterior a la historia, y eso significa no pensar en la naturaleza como algo domeñable sino algo con lo cual podemos convivir armónicamente. En lugar de ver al planeta como una inmensa reserva de energías, verlo como convergencia, como armonía. Recobrar la armonía. Eso es casi imposible. Sin embargo, quizá los poetas podríamos hacer algo por eso. No mucho, no sé 29 .

Vemos pues que las reflexiones pacistas sobre el sentido de la modernidad y la necesidad de: a) historizar su intento de imposición en todo el mundo, b) realizar la crítica de sus postulados homogeneizadores euroccidentales y, en consecuencia, c) la obligación de las civilizaciones y culturas conformadoras de la otredad de reconocer, rescatar y postular sus propias filosofías, cosmovisiones, nociones del tiempo, formas de convivencia, saberes - epistemologías, etcétera, constituyen una agenda política estrechamente vinculada a lo que años después planteara el decolonialismo.

\footnotetext{
${ }^{28}$ Ibidem, p. 295.

${ }^{29}$ Paz, O., "Blanco, Merwin, Paz: Muerte del tiempo, del tiempo de la poesía", en, Paz, O., O.C. 15, Op.cit., p.101.
} 


\section{Coincidencia crítica, distinción política}

Césaire y Paz, dos poetas nacidos en la otredad que mostraron que la crítica radical de la modernidad solo podía surgir de ahí, de esas sociedades en las que la otredad se concibe en términos multidimensionales. Si para la modernidad europea los otros son todos aquellos que habitan fuera de los confines de la civilización, invisibilizando así la multiplicidad de matices culturales e históricos existente entre y dentro de esas sociedades, para esos otros el tema es mucho más rico pues tienen absoluta claridad sobre sus singularidades que los diferencian y los hacen únicos. Así, no es lo mismo ser negro a ser mestizo, ni africano a latinoamericano u oriental, pues cada una de estas particularidades tiene sus propias especificidades histórico-culturales que las distinguen las que, bajo la mirada general impuesto bajo el concepto moderno de "universal" o mundial", palidecen hasta invisibilizarse.

Más aún. En cada una de esas singularidades existen otredades, lo cual complejiza y enriquece el análisis. Este fue uno de los temas centrales que preocupaban a Paz, si bien nosotros somos la otredad para los europeos, nosotros debemos convivir con nuestra propia otredad interna constituida por las culturas de los grupos de origen. ¿Qué hacer frente a ellos? A partir de ese cuestionamiento el poeta llegó a la conclusión de que tendríamos que caminar en la construcción de nuestra propia noción de modernidad, lo cual necesariamente implicaba alejarnos de la las categorías fundamentales impuestas por la modernidad eurooccidental, dentro de la cual el tiempo, su concepción lineal en la que el futuro es sinónimo de progreso en términos económicos, tecnológicos y de dominio de la naturaleza, habría de ser reconfigurado a fin de rescatar y reconstruir nuestras propias nociones referidas a la recuperación de la fraternidad y la sincronía con el mundo natural.

Esa recuperación de otras nociones del tiempo nos lleva al asunto de las epistemologías del sur, pues justamente el tema del tiempo es uno de los puntos axiales para aceptar la legitimidad de otras concepciones del mundo, lo cual es un elemento básico para repensar la manera en que el hombre se vincula con la naturaleza, con otros hombres y, evidentemente, con las formas de conocer la realidad. Así se abre la posibilidad de revalorar y recobrar otras formas de entender el proceso de conocimiento, diferentes a la epistemología moderna en la que el discurso científico se ha arrogado el monopolio de definir qué saberes son válidos y cuáles no. Estas reflexiones no son fáciles de hacer pues obligan a los sujetos a verse en su historicidad y, finalmente, a resignificar todo el conocimiento adquirido y, por ende, su concepción del mundo. Tan es así que para el pensamiento crítico moderno (eurooccidental) es prácticamente imposible hacerlo pues significa renunciar a sus certidumbres, las cuales ha hegemonizado exclusivamente a partir de imponer históricamente relaciones inequitativas de poder. 
El pensamiento poético, coincidirían Césaire y Paz, es la herramienta que permite otear a la otredad para ubicar en ella todo lo que es necesario no únicamente para comprender al mundo, sino para transformarlo. Sin duda, el poeta mexicano pensó y desarrolló grandemente los temas que la modernidad -y finalmente el colonialismo- representan para los países conformadores de la otredad. Creo que es tiempo de reconocerlo y asumir su reflexión acerca del fundamental ejercicio de recuperar y acendrar nuestras convicciones culturales como parte axial de la lucha política por la construcción de un mundo distinto, pensando desde lógicas diferentes a las que desde hace siglo se han impuesto como hegemónicas, esto es, para decirlo con palabras hoy vigentes en el vocabulario del análisis social progresista: consolidar y engrandecer la teoría de la decolonización con base en el pensamiento enriquecido por la poesía y pasión crítica de Octavio Paz. 


\section{Referencias bibliográficas:}

Bosquet, Alain, "Octavio Paz o el surrealismo telúrico", en, Santí, E. M. Comp. (2009), Luz espejeante. Octavio Paz ante la crítica, México: ERA.

Césaire, Aimé, (2006), Discurso sobre colonialismo, España: Akal.

Cortázar, Julio, "Homenajea a una estrella de mar", en, Santí, E. M. Comp. (2009), Luz espejeante. Octavio Paz ante la crítica, México: ERA.

De Sousa, Boaventura, (2009), Una epistemología del sur, México: CLACSO /Siglo XXI.

De Sousa, Boaventura, (2013), Descolonizar el saber, reinventar el poder, Chile: TRILCE.

Dussel Enrique, (2007), Política de la liberación. Historia mundial y crítica, Madrid: Trotta.

Lafaye, Jaques, (2013) Octavio Paz en la deriva de la modernidad, México: FCE.

Matamoro, Blas, “El ensayista Octavio Paz”, en, Santí, E. M. Comp. (2009), Luz espejeante. Octavio Paz ante la crítica, México: ERA.

Mignolo, Walter D., "El giro gnoseológico decolonial: la contribución de Aimé Césaire a la geopolítica y la corpo-política del conocimiento", en, Césaire, Aimé, (2006), Discurso sobre colonialismo, España: Akal.

Paz Octavio, (1981) "Blanco, Merwin, Paz: Muerte del tiempo, del tiempo de la poesía", en, Obras Completas (OC), T.15, México: Fondo de Cultura Económica.

(1983) Los signos en rotación y otros ensayos, Alianza, España.

(1987) Los hijos del limo, México: Seix Barral.

(1993) Itinerario, México, Fondo de Cultura Económica.

(2003) "Un escritor incómodo" (Entrevista a Danubio Torres Fierro, 1991), en, O.C. 15, México: Fondo de Cultura Económica.

(2003) "Poesía, pintura, música, etcétera." (Entrevista de Manuel Ulacia), en O.C.15.

Rodríguez, L., Xavier, (1996), El pensamiento político de Octavio Paz. Las trampas de la ideología, México: UNAM / Plaza y Valdés.

(2008) "El lunar del sol. La otredad de la historia", en Vergara G., comp., Visiones de Octavio Paz, México: Porrúa.

Santí, Enrico Mario, Comp. (2009), Luz espejeante. Octavio Paz ante la crítica, México: ERA.

Sheridan, Guillermo, (2015), Poeta con paisaje. Ensayos sobre la vida de Octavio Paz, T. 1, México: Era.

Vergara, Gloria, Comp. (2008), Visiones de Octavio Paz, México: Porrúa. Zaid, Gabriel, "La emancipación cultural”, en, Santí, E. M. Comp. (2009), Luz espejeante. Octavio Paz ante la crítica, México: ERA. 
Zambrano, María, "Un descenso a los infiernos", en, Santí, E. M. Comp. (2009), Luz espejeante. Octavio Paz ante la crítica, México: ERA.

Zea Leopoldo, "Paz: a lo universal por lo profundo.", en, Santí, E. M. Comp. (2009), Luz espejeante. Octavio Paz ante la crítica, México: ERA. 